\title{
FREQUENCY AND AETIOLOGY OF HYPERCALCAEMIA
}

\section{McNeilly JD ${ }^{1}$, Boal $\mathrm{R}^{2}$, Shaikh $\mathrm{MG}^{2}$, Ahmed $\mathrm{SF}^{2}$}

${ }^{1}$ Dept of Clinical Biochemistry, Queen Elizabeth University Hospital, Greater Glasgow \& Clyde NHS Trust, Glasgow, G51 4TF, UK

${ }^{2}$ Developmental Endocrinology Research Group, Royal Hospital for Sick Children, University of Glasgow, G3 8SJ, UK

Key words: hypercalcaemia, paediatrics

What is known about this topic: - Hypercalcaemia is uncommon in childhood.

Aetiology of hypercalcaemia is diverse

What this study adds: - Sustained hypercalacemia affects 1 in 500 children in a general hospital setting

$$
\begin{aligned}
& \text { The aetiology of hypercalcaemia differs markedly with age } \\
& \text { The cause of childhood hypercalcaemia is very different to that of adults }
\end{aligned}
$$

\section{Word Count: 1,801}

Address for correspondence

Dr Jane D McNeilly

Department of Biochemistry, level 1 SGH \& FM Building,

Queen Elizabeth University Hospital, 1345 Govan road

Glasgow G51 4TF

j.mcneilly@nhs.net

01413549047 


\section{ABSTRACT}

BACKGROUND: Hypercalcaemia is rare in children and may present with characteristic signs/symptoms or coincidentally following investigations for a variety of non-specific conditions. The aetiologies of childhood hypercalcaemia are diverse. Untreated sustained hypercalcaemia has serious clinical consequences. However there is limited data regarding the true frequency and aetiologies of childhood hypercalcaemia.

AIM: To determine the frequency of severe childhood hypercalcaemia in routine clinical practice.

METHODS: The laboratory database was searched for all children (0-17 yrs) with severe hypercalacemia defined as non-adjusted $\geq 2.90 \mathrm{mmol} / \mathrm{L}$ from 2007-2012. Hypercalcaemia was categorised as either transient ( 1 day) or sustained ( $\geq 2$ consecutive days). Retrospective analysis of all cases of sustained severe hypercalcaemia was performed to identify the underlying aetiology.

RESULTS: Over the $5 \mathrm{yr}$ period, 206 children were identified as severely hypercalcaemic $\geq 2.90 \mathrm{mmol} / \mathrm{L}(0.3 \%$ all 61,380 calcium requests). Of these $131(63.3 \%)$ children were classified as having sustained hypercalcaemia. The frequency of severe hypercalcaemia was highest in neonates ( $42 \%$ of sustained cases) and was inversely related to age. Sepsis was the most common aetiology (24\%), particularly in neonates where it accounted for $41 \%$ of all causes of neonatal hypercalcaemia. Endocrine aetiologies included congenital adrenal hyperplasia(CAH) (2 cases), fat necrosis (1), Addisons' disease (2). A genetic cause was identified in 3 children (2 Familial hypocalciuria hypercalcaemia, 1 Williams syndrome.

CONCLUSION: Sustained hypercalcaemia affects 1 in 500 children in a general hospital setting. The frequency was highest in neonates and underlying aetiology differed markedly with age. All children with sustained hypercalcaemia require thorough investigation to determine the underlying aetiology to ensure appropriate management. 


\section{INTRODUCTION}

Hypercalcaemia is an uncommon finding in children, however the clinical significance is likely greater in younger patients, [1]. The aetiology of childhood hypercalcaemia is diverse in comparison to adults where hyperparathyroidism and malignancy account for $90 \%$ of all cases, [2-4]. Furthermore the cause of childhood hypercalcaemia may be age-related, with many cases suspected of having an underlying genetic origin, [5]. The clinical presentation is often insidious and non-specific with the most frequently encountered features including lethargy, polyuria/polydipsia, vomiting, constipation and abdominal and bone pains, [5]. In addition, as calcium is often not included in local routine biochemistry urea and electrolyte(U\&E) profiles, hypercalcaemia may go undiagnosed particularly in children who appear asymptomatic.

Normal calcium homeostasis is maintained by dynamic interactions between parathyroid, renal and skeletal factors, [1]. The principal calciotrophic hormonesinfluencing these feedback processes are parathyroid hormone (PTH) and 1,25dihydroxyvitamin $D_{3}$, the active metabolite of vitamin $D,[5,6]$. Any factor disrupting this finely tuned mechanism can have major significances. Untreated hypercalcaemia of any cause can have serious clinical consequences, ranging in severity from non-specific fatigue and nausea to renal complicationsand neurological sequeale, [6].

To date there is no consensus definition of hypercalcaemia in paediatrics $[1,8]$. This factor may help explain thelimitedreliable data on the relative frequency and the different aetiologies causing hypercalcaemia in childhood.

The principal aim of this retrospective study was to determine the frequency and categorise the different causes of childhood hypercalcaemiain a tertiary hospital environment. In addition, we sought to determine if appropriate biochemical parameters were requested following identification of hypercalcaemia. 


\section{METHODS}

Laboratory databases (Royal Hospital for Sick Children (RHSC), Glasgow) were searched retrospectively for all total (unadjusted) calcium requests on children ( $<17$ yrs) over a 5 year period (2007-2011). During this period, calcium was part of the routine biochemistryurea and electrolyte (U\&E) profile. Normal calcium reference intervals derived from healthy infants and children were defined as $2.2-2.7 \mathrm{mmol} / \mathrm{L}$ for infants $(<1 \mathrm{yr})$ and $2.2-2.6 \mathrm{mmol} / \mathrm{L}$ for children (1-18yr) $[7,8]$. Therefore, hypercalcaemia was defined as mild( $\geq 2.9-3.1 \mathrm{mmol} / \mathrm{L})$; moderate $(\geq 3.2-3.5 \mathrm{mmol} / \mathrm{L})$ or severe $(>3.5 \mathrm{mmol} / \mathrm{L})$ and categorised as transient(1day) or sustained( $\geq 2$ consecutive days). Hospital information systems and clinical records were reviewed to determine where possible the aetiology of sustained hypercalcaemia and modalities of treatment implemented. The causes of hypercalcaemia were broadly categorised as endocrine, renal, oncological, iatrogenic (cardiac), suspected sepsis (determined by clinical review) and other causes of hypercalcaemia. Plasma total calcium was measured by Arsenazo III methodology on the Abbott Architect ci8000, with inter and intra assay imprecisions of $<2.0 \%$ and $<1.50 \%$ respectively. Where available other bonerelated biochemical parameters including phosphate, alkaline phosphatase (ALP), PTH, Vitamin D and urinary calcium/creatinine ratio were documented with the corresponding elevated calcium result.Thisretrospective laboratory audit aimed to identify the number of cases, causes and appropriate investigation of hypercalcaemia in a paeditatric population. As this study was part of a health service evaluation, ethical approval was not required.

\section{RESULTS}

Of the 61,380 children who had $\geq 1$ calcium requests over the 5 year period, 206(0.33\%) were identified as hypercalcaemic with a total calcium $\geq 2.90 \mathrm{mmol} / \mathrm{L}$. $165(0.27 \%)$ children were classified as having a mild hypercalcaemia, with $25(0.04 \%)$ children defined moderate and $16(0.02 \%)$ defined as severely hypercalcaemic. Of the 206 children identified, $131(63.6 \%)$ were classified as having sustained hypercalcaemia (elevated calcium for $\geq 2$ consecutive days), giving an overall frequency of 1 case per 500 children. The cause of sustained hypercalcaemia defined under broad categories according to the age is outlined in Table 1. 


\begin{tabular}{|l|c|c|c|c|c|c|c|}
\hline Age & Endocrine & Renal & Oncological & $\begin{array}{c}\text { latrogenic } \\
\text { (Cardiac) }\end{array}$ & Sepsis & Other & Total \\
\hline \hline$<28$ days & 1 & 3 & 2 & 11 & 23 & 15 & 55 \\
\hline $\mathbf{2 8 d - 1 y r}$ & 2 & 3 & 1 & 10 & 5 & 11 & 32 \\
\hline $\mathbf{1 - 5 y r}$ & 2 & 9 & 5 & 0 & 1 & 1 & 18 \\
\hline $\mathbf{6 - 1 2 y r}$ & 2 & 7 & 3 & 0 & 3 & 1 & 16 \\
\hline $\mathbf{1 3 - 1 7 y r}$ & 2 & 5 & 1 & 2 & 0 & 0 & 10 \\
\hline Total & $\mathbf{9}$ & $\mathbf{2 7}$ & $\mathbf{1 2}$ & $\mathbf{2 3}$ & $\mathbf{3 2}$ & $\mathbf{2 8}$ & $\mathbf{1 3 1}$ \\
\hline
\end{tabular}

Table 1.Aetiology of hypercalcaemia according to age.

The frequency of sustained hypercalcaemia was highest in neonates $(55 / 131 ; 42 \%$ of all sustained cases) and was inversely related to age (figure 1). Suspected neonatal sepsis was the single commonest cause $(23 / 131 ; 24 \%)$ of hypercalcaemia. In the majority of children $>1 \mathrm{yr}$, the cause of sustained hypercalcaemia due to their underlying condition (renal; tertiary hyperparathyroidism or oncological), or iatrogenic relating to their treatment regimen (e.g. cardiac aetiologies). 28(21.4\%) cases were categorised as "other" with surgery (neuro- or gastro-) being the highest single cause (11 cases). A primary respiratory, metabolic or gastroenterological cause was implicated in 7 cases. Prematurity was thought the likely aetiology in a further 4 cases. The underlying cause of 2 cases of sustained hypercalcaemia remains unknown but is likely multi-factorial with a both children having a number of co-morbidities.

Conditions associated with sustained hypercalcaemia encountered by the endocrine service included 3 cases of adrenal insufficiency, 2 cases of familial hypocalciuric hypercalcaemia (FHH) and individual cases of idiopathic "unknown" hypercalcaemia, subcutaneous fat necrosis and Williams-Beuren Syndrome. One child had numerous pathologies on presentation including thyrotoxicosis and nephrocalcinosis.

In terms of severity of hypercalcaemia, the majority $111 / 131$ (84.7\%) of children were classified as mild(2.9-3.1 mmol/L) with 13(9.9\%) identified as moderate(3.2-3.5 mmol/L) and 7(5.4\%) severe(>3.5 mmol/L)(Table 2 ). 


\begin{tabular}{|c|c|c|c|c|}
\hline Age & $\begin{array}{c}\text { Mild } \\
(\geq 2.9-3.1 \mathrm{mmol} / \mathrm{l})\end{array}$ & $\begin{array}{c}\text { Moderate } \\
(3.2-3.5 \mathrm{mmol} / \mathrm{L})\end{array}$ & $\begin{array}{c}\text { Severe } \\
\text { (>3.5 mmol/L) }\end{array}$ & Total \\
\hline <28days & 53 & 1 & 1 & 55 \\
\hline 28 days - 1yr & 29 & 1 & 2 & 32 \\
\hline $1-5 y r$ & 9 & 6 & 3 & 18 \\
\hline $6-12 y r$ & 11 & 4 & 1 & 16 \\
\hline $13-17 \mathrm{yr}$ & 9 & 1 & 0 & 10 \\
\hline Total & 111 & 13 & 7 & 131 \\
\hline
\end{tabular}

Table 2. Severity of hypercalcaemia classified by age

There was no correlation between underlying cause and severity of hypercalcaemia with 2 cases of severe hypercalcaemia due to management following cardiac surgery (iatrogenic), 2 due to renal complications and 3 endocrine related conditions

Algorithms for investigating hypercalcaemia frequently include analysis of PTH, vitamin D and/or urinary calcium/creatinine ratios to aid the differential diagnosis, [1,5]. Of the 131 children identified as having sustained hypercalcaemia, PTH alone was analysed in 43 (32.8\%) whereas 12/131 (9.2\%) had both PTH and vitamin D. Vitamin D deficiency (i.e.<25 $\mathrm{nmol} / \mathrm{L})$ was noted in 2 patients, 3 were classified as vitamin $D$ insufficient (25-50 nmol/L) with the remaining 7 patients have sufficient vitamin $D$ concentrations (>50 nmol/L). No children had vitamin D intoxication, a known cause of hypercalcaemia. Only $11 / 131$ (8.4\%) patients had PTH, vitamin D and urinary calcium/creatinine results, the underlying aetiology of each patient is showing in Table 3. There was no correlation between age, severity, cause, duration of hypercalcaemia or requesting speciality and performance of additional biochemical tests (i.e. PTH, vitamin D, urinary calcium/creatinine ratio).

\begin{tabular}{|l|c|l|}
\hline Severity of Hypercalcaemia & Number of patients & Aetiology \\
\hline Mild ( $\geq 2.9-3.1 \mathrm{mmol} / \mathrm{l})$ & 4 & $\begin{array}{l}\text { latrogenic (cardiac), oncology } \\
\text { "other" } \times 2\end{array}$ \\
\hline Moderate $(3.2-3.5 \mathrm{mmol} / \mathrm{L})$ & 3 & Oncology, endocrine $\times 2$ \\
\hline
\end{tabular}


Table 3. The aetiology of hypercalcaemia in children who underwent comprehensive biochemical assessments (PTH, Vitamin D and urinary calcium/creatinine), categorised according to severity.

\section{DISCUSSION}

Hypercalcaemia is an uncommon finding in paediatrics. The often non-specific symptoms, diverse age-related aetiologies and lack of calcium in many routine biochemistry U\&E profiles may delay diagnosis and implementation of appropriate treatments. Consequently the true frequency of childhood hypercalcaemia in a tertiary hospital setting is to date unclear.

The current retrospective study which included over 61,000 children, illustrated the rarity of hypercalcaemia (>2.9 mmol/L) with only 203 (0.33\%) cases over a 5yr period. Sustained hypercalcaemia, i.e. hypercalcaemia over $\geq 2$ consecutive days, affected 1 in 500 children in a general hospital setting.

The underlying aetiologies of sustained hypercalcaemia were diverse, ranging from renal failure (e.g. tertiary hyperparathyroidism) and malignancy to iatrogenic causes including Total Parental Nutrition (TPN), [5]. Suspected neonatal sepsis, defined by clinical judgement was the single most common cause (41\%) of hypercalcaemia however sepsis/infection alone is not routinely included as one of the common causes of hypercalcaemia in neonates and infants, $[1,9]$. The possible mechanisms causing the sustained hypercalcaemia may include extra-renal production of $1,25(\mathrm{OH})_{2} \mathrm{D}$ by infiltrating macrophages, [1], and/or release of cytokines such as interleukin 6 (IL-6) increasing osteoclastic activity, thus bone resorption and calcium release, [5].

Only nine cases of sustained hypercalcaemia were categorised as endocrine-related, causes of which included congenital adrenal hyperplasia (CAH)(2), autoimmune Addisons' disease (1) and subcutaneous fat necrosis (1). Hypercalcaemia due to a genetic cause was identified in three children. A heterozygous in-activating mutation in the calcium sensing receptor (CaSR) causing familial Hypocalciuric hypercalaemia (FHH) was found in two children. Diagnosis of Williams-Beuren was confirmed by the presence of a deletion on chromosome 
7q11.23, [10]. The underlying cause of one case remains unknown. This patient has presented to A\&E on at least 3 separate occasions over the 5 year period with a short history of non-specific symptoms including constipation, weight loss and leg pain. On each occasion, the severe hypercalcaemia (total calcium ranging from 4.9-5.6 mmol/L) was successfully treated with IV fluids, diuretics (Frusemide) and bisphosphonates (Pamidronate), $[5,11]$. The patient was discharged on a low calcium diet and vitamin $D$ (Dalavit) and remained asymptomatic for a period of 1-2 years before re-presenting. Genetic studies, imaging (ultra-sound, chest $x$-ray, sestamibi scan) and biochemistry (catecholamines, tumour markers, ACE, PTH-rP) were all normal. Further genetic investigations are in progress.

The relationship between age of child and frequency of hypercalcaemia has not previously been reported. $66 \%$ of all cases of sustained hypercalcaemia in this study were $\leq 1 \mathrm{yr}$, whereas only $7.6 \%$ were adolescents $(13-17 y r s)$. There is the potential that the reported age-related phenomenom was subject to some population bias due to the specialist neonatal facilities provided in the study hospital. Of note, $22.8 \%$ of all calcium requests were from children $<1 \mathrm{yr}$. Furthermore it is possible that some adolescents with chronic conditions such as renal failure may have been transitioned to adult physicians for the management of disease therefore would not be identified in this study cohort.

There is a clear age-related aetiological phenomenon of hypercalcaemia with sepsis and "other" esoteric causes accounting for $69 \%$ of all cases of sustained hypercalcaemia in neonates. In contrast, no cases of sepsis or "other" esoteric causes were identified as the primary origin of sustained hypercalcaemia in adolescents (13-17yrs). This age-related finding supports those of Lietmanet al, [1], whose study propose differential diagnostic tables for infants <2yr and children. Interestingly, in the study by Lietmanet al, [1],sepsis alone was not included as a potential cause of hypercalcaemia in any age group, suggesting it may not be considered as the underlying cause of hypercalcaemia and may result in further unnecessary investigations. A further interesting finding in this study population of $>61,000$ children was there were no cases of primary hyperparathyroidism, one of the principal causes of hypercalcaemia in adults. This may be due to the limited number of children who had both calcium and PTH measured (43/131 children, 32.8\%). Despite this 
limitation, it highlights the importance of appreciating paediatrics/children as a speciality when considering a differential diagnosis of hypercalcaemia.

Additional biochemical tests are frequently suggested when investigation the potential cause of hypercalcaemia, $[1,5]$. The reasons why only $(32.8 \%)$ of children with sustained hypercalcaemia had PTH requested remains unclear however potential factors may include the underlying cause of hypercalcaemia already being known by the requesting physician (i.e. tertiary hyperparathyroidism or iatrogenic)therefore additional investigations were not required for appropriate patient management and/or the additional sample volume required for this test. The lack of vitamin $D$ requests noted in the study population, only $9.2 \%$ of all cases, may relate to lack of availability of Vitamin D analysis on-site during the time of the audit (2007-2012). Furthermore, the nature of the methodology used in at referral hospital required a pre-analytical solid phase extraction step, thus a relatively large sample volume $(300 \mu \mathrm{l})$. As numerous analytes are often requested on single, small paediatric samples obtaining sufficient volume for send-away tests is a continual problem.

\section{CONCLUSION}

This study of $>61,000$ calcium requests demonstrated that sustained childhood hypercalcaemia is rare with a frequency of 2.1 cases per 1,000. Hypercalcaemia was inversely-related to age, with the highest occurrencein neonates. The underlying aetiologies differ markedly with age with neonatal sepsis being the single most common cause. Although many of these conditions are uncommon, it is important all children with sustained hypercalcaemia, where the condition is not associated with their medical treatment,receivethorough and expert investigation to determine the underlying aetiology.

Acknowledgements: We would like to acknowledge $\mathrm{Mr}$ C Hall for his assistance with data gathering.

Competing Interests: None of the authors have any conflict of interest

\section{REFERENCES}


1. Lietman SA, Germain-Lee E, Levine MA. Hypercalcaemia in Children and Adolescents. CurrOpinPediatr. (2010) 22(4):508-515.

2. NICE Guidelineshttp://cks.nice.org.uk/hypercalcaemia\#!topicsummary laccessed May 2015)

3. Kollars J, Zarroug AE, van HeerdenJ,et al. Primary hyperparathyroidism in pediatricpatients.Pediatrics. 2005;115(4):974-80.

4. Mallet E.Primary hyperparathyroidism neonates and childhood. The French experience (1984-2004). Horm Res.2008;69(3):180-8,

5. Davies JH, Shaw NJ. Investigation and management of hypercalcaemia in children. Arch Dis Child (2012) 97:533-538.

6. Reynolds BC, Cheetham TD. Bones, stones, moans and groans: hypercalcaemiarevisited. Arch Dis Child EducPract Ed. 2015;100(1):44-51.

7. Rodd C, Goodyer P. Hypercalcemia of the newborn: etiology, evaluation, and management. PediatrNephrol 1999; 13(6):542-7

8. Colantonio DA, Kyriakopoulou L, Chan MK et al. Closing the gaps in pediatric laboratory reference intervals: a CALIPER database of 40 biochemical markers in a healthy multiethnic population of children. Clin Chem. 2012;58(5):854-868

9. Pathology Harmony Group. Harmony of reference intervals 2012. http://www.pathologyharmony.co.uk

10. Francke U. Williams-Beuren syndrome: genes and mechanisms. Hum $\mathrm{Mol}$ Genet.1999;8(10):1947-54

11. Makras P, Papapoulos SE. Medical treatment of hypercalcaemia. Hormones (2009) 8(2):83-95. 